\title{
Leaf litter quality coupled to Salix variety drives litter decomposition more than stand diversity or climate
}

\author{
Stefanie Hoeber (D) Petra Fransson • Martin Weih • \\ Stefano Manzoni
}

Received: 16 January 2020 / Accepted: 12 June 2020 /Published online: 22 June 2020

(C) The Author(s) 2020

\begin{abstract}
Aims Decomposition of leaf litter is influenced by litter quality as determined by plant genotype and environment, as well as climate and soil properties. We studied these drivers of decomposition in communities of Salix varieties, hypothesizing that decomposition rates would increase under warmer climate, in more diverse communities, and with increasing litter quality of the individual varieties.

Methods Litter from four Salix varieties was incubated in three field trials across a latitudinal gradient from
\end{abstract}

Responsible Editor: Luca Bragazza.

Electronic supplementary material The online version of this article (https://doi.org/10.1007/s11104-020-04606-0) contains supplementary material, which is available to authorized users.

S. Hoeber $(\bowtie) \cdot$ M. Weih

Department of Crop Production Ecology, Swedish University of Agricultural Sciences, Ulls väg 16, 75007 Uppsala, Sweden

e-mail: Stefanie.hoeber@slu.se

P. Fransson

Department of Forest Mycology and Plant Pathology, Uppsala

BioCenter, Swedish University of Agricultural Sciences, Almas

Allé 5, 75007 Uppsala, Sweden

S. Manzoni

Department of Physical Geography, Stockholm University, Svante Arrhenius väg 8, 10691 Stockholm, Sweden

S. Manzoni

Bolin Centre for Climate Research, Stockholm University, Svante Arrhenius väg 8, 10691 Stockholm, Sweden
Central to Northern Europe. Litter and stand properties were measured and used as predictors of decomposition. Results No significant site differences in remaining mass or nitrogen were found. Instead, effects of initial leaf litter quality on decomposition were stronger than climatic effects. Litter quality of individual varieties strongly affected decomposition, while increasing litter diversity did not.

Conclusions Decomposition was controlled by variety identity depending on site, indicating that local soil conditions affect litter quality (and thus decomposition) more than macroclimate. In mixed communities, varieties producing fast-decomposing litter enhanced the litter decomposition of other components producing slowdecomposing litter, and vice versa. This implies that site conditions partly determine which varieties affect community-level decomposition and nutrient release.

Keywords Leaf litter · Decomposition · Salix · Genetic diversity $\cdot$ Latitudinal gradient $\cdot$ Litter mixing

\section{Introduction}

Leaf litter decomposition is an important step in the cycling of elements in the biosphere, and the regulation of this process can have broad ecosystem-level consequences. On the one hand, litter decomposition releases nutrients chemically bound to carbon (C) (Manzoni et al. 2010; Parton et al. 2007), which are thus made available to plants in mineral form. On the other hand, the fraction of litter that is not respired by the 
decomposer community can become sequestered in the soil over the long term (Berg and McClaugherty 2003; Cotrufo et al. 2013). Therefore, it is important to understand the factors controlling litter decomposition - specifically macroclimate, litter quality or leaf traits.

Traditionally, these factors have been considered in decomposition studies focusing on the degradation of individual leaf litter types across sites (Aerts 1997; Cornwell et al. 2008; Djukic et al. 2018; Makkonen et al. 2012; Parton et al. 2007; Zhang et al. 2008). These studies found that macroclimatic conditions, litter quality driven by both chemical (e.g., lignin concentration, C:N and C:P ratio), or non-chemical leaf traits (e.g., leaf mass to area ratios) could be the dominant factors controlling decomposition. Regarding macro-climatic conditions, microbial activity and thus decomposition are stimulated under warm and moist conditions (Aerts 1997; Parton et al. 2007; Zhang et al. 2008), so we can expect that decomposition rates decrease moving North from central to northern Europe. However, evidence also points to indirect effects of climatic conditions climate affects plant community composition and local nutrient cycling, which in turn determine decomposition rates (Makkonen et al. 2012).

The recognition that under natural conditions, litter from a given species is not degraded in isolation, led to studies following decomposition of litter mixtures in a given environment (Ball et al. 2009; Gartner and Cardon 2004; Handa et al. 2014; Jacob et al. 2009; Porre et al. 2020). These studies show that in some (but not all) systems, litter mixtures can decompose faster than would be expected based on community-component rates in isolation (synergistic effects), though these effects are not ubiquitous and are difficult to predict (Porre et al. 2020). Litter mixtures were also used to test the role of plant diversity on decomposition (Handa et al. 2014; Joly et al. 2017; Setiawan et al. 2016). The general conclusion from these studies was that species richness per se did not affect decomposition, but that a diverse plant community directly (through litter quality) and indirectly (by changing micro-environmental conditions) affected - and often promoted - decomposition. For example, high quality litter (with high $\mathrm{N}$ or $\mathrm{P}$ concentrations) often promotes decomposition of litter mixtures, whereas low quality litter with high lignin concentrations is more difficult to degrade (Berg and McClaugherty 2003) and can thus inhibit decomposition. Interestingly, macro-climatic conditions can be less important as predictors of decomposition rate than the micro-environmental conditions set by the plant community (Joly et al. 2017).

To further assess the interaction between decomposition and the plant community (which cannot be done by incubating litter mixtures in the same environment), litter and plant mixtures have to be combined, by incubating different mixtures in environments with varying plant diversity (Barantal et al. 2011; Jewell et al. 2017; Scherer-Lorenzen 2008; Vivanco and Austin 2008). These studies confirmed that plant community diversity per se did not affect decomposition, while plant functional diversity did. Moreover, native litter from the same plant community-component occurring at any given site was found to decompose more rapidly - the socalled 'home field advantage' (Austin et al. 2014). This finding underlines how important the microenvironment created by a specific plant community is for decomposing its own litter.

The above cited studies focus on inter-specific litter mixtures, but how is decomposition affected by intraspecific variability? Decomposition rates can vary across genotypes because of direct genetic effects on litter chemistry (Crutsinger et al. 2009; Madritch and Hunter 2005; Silfver et al. 2007), indirect effects mediated by decomposer preferences for litter from certain genotypes (Wang et al. 2014), and indirect effects mediated by the environment created by the plant community (LeRoy and Fischer 2019). Variations in decomposition rates across genotypes tend to be smaller than across species in different genera (Crutsinger et al. 2009; Li et al. 2017), but comparable or larger than variations across congeneric species (LeRoy et al. 2012). Similar to conclusions drawn for inter-specific litter mixtures, in some cases non-additive effects are observed in genotype mixtures, but without a consistent pattern (Li et al. 2017; Madritch et al. 2006; Madritch and Hunter 2005; Schweitzer et al. 2005; Wang et al. 2014). Moreover, genotype diversity per se has less predictive power for decomposition rates than genotype identity (Crutsinger et al. 2009; Madritch et al. 2006; Madritch and Hunter 2005), with some exceptions (Wang et al. 2014).

As litter $\mathrm{C}$ - and thus mass - is lost during decomposition via respiration, nutrients (specifically $\mathrm{N}$ and $\mathrm{P}$ ) are immobilized and subsequently released by the decomposers. Litter diversity may either enhance or reduce nutrient release compared to the expected average based on the behaviour of individual litter types. However, diversity effects vary depending on litter mixture 
and incubation conditions, in both inter-specific (Gartner and Cardon 2004; Schweitzer et al. 2005) and intra-specific mixtures (Crutsinger et al. 2009; Madritch et al. 2006; Schweitzer et al. 2005; Wang et al. 2014). This indicates that litter (or host community) diversity may alter the coupling of nutrient and $\mathrm{C}$ dynamics that characterizes decomposition. In other words, how much $\mathrm{N}$ and $\mathrm{P}$ is released per unit $\mathrm{C}$ lost does not only depend on litter chemistry as previously shown (Manzoni et al. 2010; Parton et al. 2007), but also on litter diversity. However, when and how this coupling of nutrients and $\mathrm{C}$ during decomposition might change with litter diversity is not clear.

As reviewed in the preceding paragraphs, three groups of potential controlling factors for decomposition and nutrient mineralization can be identified: i) macroclimate, ii) the characteristics of the litter represented by the community components (here Salix varieties), and iii) the micro-environmental conditions set by the plant community at the site of decomposition. Which of these three groups of factors is more important for explaining mass loss and nutrient mineralization remains an open question, and frames the scope of this contribution. To this aim, we manipulated litter and plant diversity in a short-rotation coppice system, where four varieties of willow (Salix spp.) were grown in all possible combinations (all four monocultures, two-, three- and four-mixtures, 15 in total) at three sites distributed over 12 degrees of latitude. This design allows us to test if diversity effects are consistent across climatic and edaphic conditions. Litter from each monoculture or mixture was incubated in the same plot where it originated from, providing a range of litter chemical properties (resulting from mixing of four varieties with contrasting foliar traits), and community compositions (one to four variety mixtures). The rationale for using willow varieties as the community-components is twofold: i) because willows are economically relevant for biomass production (Kuzovkina et al. 2008), understanding decomposition and nutrient release in these systems could help improving their management; and ii) thanks to the differences among their functional traits (e.g., leaf nitrogen concentration, leaf area productivity), they offer an opportunity to study the effect of genetic (here variety) diversity on litter decomposition (Weih et al. 2019).

According to the above mentioned factors controlling decomposition, we expected that $(\mathrm{Hl})$ litter decomposition rate is strongly affected by climate and decreases along a latitudinal gradient from Central (more favourable climate for decomposition) to Northern Europe (less favourable climate); (H2) litter variety identity is a strong driver of decomposition, and differences in decomposition among litters are conserved across the latitudinal gradient; $(H 3)$ litter decomposition increases with increasing genetic litter diversity thanks to synergistic effects, while $\mathrm{N}$ retention in litter improves with litter diversity because $\mathrm{N}$ mineralized from $\mathrm{N}$-rich litter is immobilized by N-poor litter in the same litter bag; and (H4) the effect on litter decomposition of adding individual varieties to a mixed stand varies among varieties based on litter quality differences, i.e., the addition of some varieties increases decomposition rate while other varieties decrease it.

\section{Materials and methods}

Study sites and plant material

Three field trials were established on arable land in

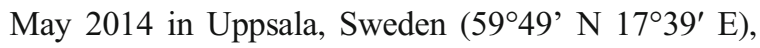
Rostock, Northern Germany $\left(54^{\circ} 02^{\prime} \mathrm{N} 12^{\circ} 05^{\prime} \mathrm{E}\right)$, and Freiburg, Southern Germany (48 $01^{\prime}$ N $7^{\circ} 49^{\prime}$ E) (Fig. $\mathrm{S} 1)$. For each field trial, daily mean temperature and daily total precipitation were measured by the nearest climate station (Fig. S2). Long-term mean climatic conditions at the three sites are summarized in Table S1. Four varieties of Salix, partly differing at species or intra-specific levels, were used as the stand components: $\mathrm{A}=$ 'Björn' (Salix schwerinii E. Wolf. $\times S$. viminalis L.), $\mathrm{B}=$ 'Jorr' (S. viminalis $), \mathrm{C}=$ 'Loden' $(S$. dasyclados Wimm.) and $\mathrm{D}=$ 'Tora' $(S$. schwerinii $\times S$. viminalis $)$. 'Björn' and 'Tora' are taxonomically closely related as they derive from the same parent material and are siblings but differ in their morphological (leaf area, stem diameter) and functional characteristics (e.g., leaf $\mathrm{N}$ concentration). 'Jorr' is more closely related to the siblings 'Björn' and 'Tora', whereas 'Loden' belongs to a different species and thus is taxonomically most distant from the other three varieties (Larsson 1998). Leaf element concentrations have been shown to vary among the varieties investigated here; e.g., in a pot experiment, the $\mathrm{N}$ concentration in 'Björn' leaves was found to be higher than in the leaves from the three other genotypes, followed by 'Jorr', 'Tora' and 'Loden' (Weih and Nordh 2002). However, the leaf element concentrations of these Salix varieties is indeed affected more by the 
environment than genotype, as was shown in a field trial in Sweden (Ågren and Weih 2012).

All varieties were planted in monoculture and all possible mixtures (2-, 3- and 4-variety-mixtures), and arranged in a randomized blocked design with a total of 45 plots over three blocks in Uppsala and Freiburg (Fig. S1). In Rostock only 'Loden' and 'Tora' were grown, resulting in a total of 9 plots. Plots measured $9.6 \mathrm{~m} \times$ $9.6 \mathrm{~m}$ and contained 12 rows with 12 plants in each row with an offset every second row, resulting in a hexagonal planting pattern with equal distances of $0.8 \mathrm{~m}$ between individuals. This spacing corresponds to approximately 15,600 plants/ha. Further details about the establishment of the sites, soils and climatic conditions can be found in Hoeber et al. (2018).

\section{Decomposition litter bags and experimental design}

Decomposition was determined by incubating triangular litter mesh bags $(90 \times 90 \times 125 \mathrm{~mm} ; 50 \mu \mathrm{m}$ mesh size, Sintab Produkt AB, Malmö, Sweden) allowing for fungal and bacterial ingrowth, colonization and decomposition, but excluding root ingrowth. Litter was collected in amounts representative of the actual leaf productivity of each variety in each plot. In this way, proportions of leaf material varied slightly compared to the proportion of varieties in any given plot. Leaf proportions were estimated using allometric relations (Section Analysis of litter chemistry and decomposition data) and used to assess interactive effects on decomposition (Section Additive vs. interactive effects of mixed litters on decomposition). In Freiburg and Uppsala, leaf litter was collected in late summer and autumn of 2014 from each plot using tree nets that covered trees in the same proportion as the varieties in each plot. In Rostock, litter was hand-collected in the autumn, also ensuring that amounts representative of the leaf production were collected. Litter of all varieties for any given plot was mixed, mesh bags were filled with $1 \mathrm{~g}$ dried leaf litter, and for each plot mesh bags contained own-plot (i.e., native) litter. To enable standardized comparisons across the three sites, we also included a standard litter derived from the variety 'Loden' grown in Uppsala. Subsamples of the initial leaf litters were kept for chemical analyses. A total of 14 mesh bags in monocultures (12 containing plot-own litter and two standard litter) and 12 mesh bags in mixtures were placed on top of the soil surface in each plot in the four corners of the inner $3.2 \times 3.2 \mathrm{~m}$ quadrant (corresponding to subplot $\mathrm{q}$ in the field layout in Hoeber et al. (2018)), and secured using two metal hoops pushed into the soil across the mesh bag. The decomposition experiment started in Uppsala in December 2014 and in Freiburg and Rostock in January 2015, where mesh bags were incubated for approximately 1.5 years (June 2016; 514-564 days after incubation). After harvest, mesh bags were cleaned of soil and mineral particles using a brush and dried in an oven at $70{ }^{\circ} \mathrm{C}$ for $72 \mathrm{~h}$. The dried mesh bags from Germany were placed in airtight plastic bags and sent to Sweden for further analysis.

Litter decomposition measurements

Mass loss was determined by carefully removing leaf litters from the mesh bags and recording dry weight. A sub-sample from each mesh bag (on average $0.61 \mathrm{~g}$ ) was heated to $550^{\circ} \mathrm{C}$ for $6 \mathrm{~h}$ to combust all organic matter, in order to correct the dry weight loss for any mineral particles attached to the litter. All reported concentrations and remaining mass ratios are calculated on an ashfree dry mass basis. Initial leaf litter was analysed for total carbon $(\mathrm{C})$, nitrogen $(\mathrm{N})$, phosphorus $(\mathrm{P})$ and lignin content. A subsample of $0.17 \mathrm{~g}$ per mesh bag of the decomposed litter was used to analyse $\mathrm{C}$ and $\mathrm{N}$.

Plant biomass and leaf trait data

Stem diameters of all 144 plants per plot were measured in spring 2015, 2016 and 2017 after each growing season. In Uppsala, from 12 selected plants per plot leaf area was measured after which leaves were immediately dried in an oven at $70{ }^{\circ} \mathrm{C}$ for $72 \mathrm{~h}$. Leaf dry weight (leaf biomass) was measured to calculate specific leaf area, as leaf area per leaf biomass $\left(\mathrm{cm}^{2} / \mathrm{g}\right)$.

\section{Data analysis}

\section{Additive vs. interactive effects of mixed litters on decomposition}

When a litter bag contains more than one litter type, the overall decomposition rate may be controlled not only by the relative abundance of the different litter types, but also by possible interactive effects. For additive decomposition of $n$ litter types, the fraction of remaining mass in the litter bag at a specific sampling time is given by 


$$
\left(\frac{M}{M_{0}}\right)_{\text {additive }}=\frac{\sum_{i=1}^{n} M_{i}}{\sum_{i=1}^{n} M_{0, i}},
$$

where $M$ is the litter dry weight, subscript $i$ indicates the litter type and subscript 0 refers to initial mass. Equation (1) can be re-written to isolate the fraction of remaining mass of a specific litter type,

$$
\left(\frac{M}{M_{0}}\right)_{\text {additive }}=\sum_{i=1}^{n} \frac{M_{i} \quad M_{0, i}}{M_{0, i} \sum_{i=1}^{n} M_{0, i}}=\sum_{i=1}^{n} \alpha_{i} \frac{M_{i}}{M_{0, i}},
$$

where the fraction of the initial dry weight contributed by a given litter type is denoted by $\alpha_{i}=\frac{M_{0, i}}{\sum_{i=1}^{n} M_{0, i}}$. To proceed in the calculation of $\left(\frac{M}{M_{0}}\right)_{\text {additive }}$, both the fraction of remaining litter $\frac{M_{i}}{M_{0, i}}$ and the fractions of initial dry weight $\alpha_{i}$ must be specified. The $\frac{M_{i}}{M_{0, i}}$ is known from the incubation of litter bags in monoculture plots. In our experimental setup, the $\alpha_{i}$ were not imposed based on the community-component composition, but they reflected the abundance of fresh leaves in each plot. Thus, $\alpha_{i}$ were calculated as the fractions of fresh leaf mass for each variety in each plot (these data are available only for the Uppsala site, so the analysis is restricted to this location). If a litterbag contained litter types in equal amounts, all $\alpha_{i}$ would be the same. In contrast, a relatively higher amount of a certain litter type would cause $\alpha_{i}$ for that variety to be higher than the others.

The $\left(\frac{M}{M_{0}}\right)_{\text {additive }}$ can then be compared to the measured remaining mass, thus identifying when positive (i.e., $\left(\frac{M}{M_{0}}\right)_{\text {measured }}>\left(\frac{M}{M_{0}}\right)_{\text {additive }}$ ) or negative interactive effects $\left(\left(\frac{M}{M_{0}}\right)_{\text {measured }}<\left(\frac{M}{M_{0}}\right)_{\text {additive }}\right)$ occur during decomposition of litter mixtures. Equivalent criteria for the first order decay constants of litter mixtures are presented in the Supplementary Information.

Because there are three replicates per variety combination, there are also three replicates for each monoculture, which creates a potential ambiguity as to which replicate set should be used to calculate $\left(\frac{M}{M_{0}}\right)_{\text {additive }}$ to be compared to any given $\left(\frac{M}{M_{0}}\right)_{\text {measured }}$ in litter mixtures. To overcome this issue, we randomized the selection of the monoculture plots to be used in Eq. (2), repeating the selection 20 times (varying this number does not affect the results). Response ratios (RR) are calculated as $\left(\frac{M}{M_{0}}\right)_{\text {measured }} /\left(\frac{M}{M_{0}}\right)_{\text {additive }}$ using data from all runs; the mean RR is then compared to RR $=1$ with a t-test. In addition, for each of the 20 runs, a reduced major axis (RMA) regression is performed to extract the slope of the $\left(\frac{M}{M_{0}}\right)_{\text {measured }}$ vs. $\left(\frac{M}{M_{0}}\right)_{\text {additive }}$ relation. Finally, the mean of the RMA slopes is compared to one (by using a t-test) to assess if mixtures characterized by different decomposition rates also exhibit different interactive effects.

\section{Analysis of litter chemistry and decomposition data}

The mean fraction of remaining mass in each plot was calculated as the ratio between the mean mass remaining when the litter bags were harvested and the mean mass of leaves inserted in the litter bags before the field incubation.

The fraction of remaining mass of the standard litter type (leaf material from 'Loden' collected in Uppsala) was compared to the fraction of mass remaining in all 'Loden' monoculture plots. This comparison allows separating climatic effects (isolated by analysing the decomposition of the standard litter) from site effects affecting the local litter quality (confounded with climatic effects in the decomposition of the local litter). To test the effects of sites and varieties on initial litter chemistry $(\mathrm{N}$, $\mathrm{C}, \mathrm{P}$ and lignin), as well as decomposed litter amount and chemistry (remaining mass, $\mathrm{C}$, and N), two-way ANOVA followed by post-hoc Tukey's HSD test was used. Analyses were performed in R (version 3.6.1, R Core Team 2019).

The fraction of leaves produced by each variety in the mixed communities (used to estimate $\alpha_{i}$ in Section Additive vs. interactive effects of mixed litters on decomposition) was calculated using allometric relations. Variety specific allometric relations $y=a x^{b}$ were determined to predict the leaf mass ( $\mathrm{g} / \mathrm{plant}$, indicated by $y$ ) as a function of stem diameter $(\mathrm{mm}$, indicated by $x$ ). Coefficients and exponents are reported in Table S2.

\section{Presence and absence of genotypes}

Linear Bayesian models were used according to Hoeber et al. (2018) to calculate the probability 
and range of credible values that adding a specific Salix variety to a community with other Salix varieties would have either a positive or negative effect on average remaining mass or $\mathrm{N}$ in that community. In this analysis, we considered only the two sites where data from all four varieties were available (Freiburg and Uppsala). Model parameters allowed us to estimate remaining mass or $\mathrm{N}$ for any combination of Salix varieties where remaining mass or $\mathrm{N}$ estimates were derived for different community combinations. As a result, estimated differences for all possible community combinations with and without a specific variety could be compared. Since outputs from Bayesian models are posterior probability distributions, all variables derived from these outputs are also probability distributions. Accordingly, estimated remaining mass or $\mathrm{N}$ for each community could be subtracted from values of remaining mass or $\mathrm{N}$ in mixtures where a specific variety was present, to find the magnitude and direction of an effect of adding that variety to the community. By averaging all these differences, we derived the probability and range of estimated effect that the addition of a specific variety to a community favours an increase in the plot-level remaining mass or N. Parameters and derived variables where the posterior distribution largely overlaps zero were considered to be relatively unimportant or have little effect (Hobbs and Hooten 2015). All Bayesian models were implemented in JAGS (Plummer 2003) via the "rjags" package in R. Model convergence was checked by visual inspection of trace plots and using the Gelman and Rubin diagnostic (all estimated parameters <1.1; Gelman and Rubin 1992). Model validity was assessed using posterior predictive checks and Bayesian ' $\mathrm{P}$ ' values (Hobbs and Hooten 2015). Priors, such as previous estimated values, were weakly informative and centred on expected and calculated initial values from the field study to start the model iterations and speed up model convergence (McElreath 2015).

In addition to the Bayesian analysis, standard linear regression models were used to evaluate if the presence of specific varieties and litter chemistry affected decomposition patterns (mass and $\mathrm{N}$ remaining). Linear models were implemented in Matlab (The MathWorks, Inc., release R2018a) using the function fitlm with variety presence as categorical variables.

\section{Results}

Climatic effects on litter decomposition (H1)

Based on standard empirical relations between decomposition rates and temperature, evaporative demand and precipitation, decomposition rates in Rostock and Freiburg were predicted to be $43 \%$ and $90 \%$ faster than in Uppsala (Table S1, Fig. S3). In contrast to these expectations, litter mass and $\mathrm{N}$ remaining after 1.5 years did not differ significantly among the three sites when the comparison was made across all varieties and diversity levels (Fig. 1). Moreover, data from the standard 'Loden' litter collected in Uppsala and exposed to the site conditions at all three locations did not indicate a strong climatic effect on decomposition. This standard litter tended to decompose faster than the local 'Loden' litter in Rostock and Freiburg, but the differences were not significant (Fig. S3). Only when the comparison was made between the pure cultures of the four varieties (and regardless of variety identity) did we find significant site differences in decomposition rate, with faster litter decomposition (i.e. lower remaining mass) in Freiburg, medium decomposition in Rostock and the lowest decomposition rates in Uppsala (Figs. 2a and 3a). The pattern was similar for the fraction of remaining $\mathrm{N}$, although no significant site differences were found for remaining $\mathrm{N}$ (Figs. 2d and 3d).

Effects of variety identity on litter decomposition in Salix monocultures (H2)

Mass loss differed significantly among the four varieties (Fig. 2b, Table S3). The genetic variation in mass loss varied among the sites (e.g., significant site by variety interaction, Fig. 2c, Table S3). In Freiburg, decomposition was similar between all varieties, whereas in Uppsala decomposition differed strongly among the varieties, where 'Tora' showed the lowest decomposition rate followed by 'Björn', 'Loden' and 'Jorr', which had the highest decomposition rate (Fig. 2c).

Effects of stand diversity on litter decomposition (H3)

The fractions of remaining mass were generally similar across sites and stand diversity levels (Fig. 1a), providing no evidence for any strong or positive effect of litter diversity on decomposition. However, the more diverse 


\section{a}
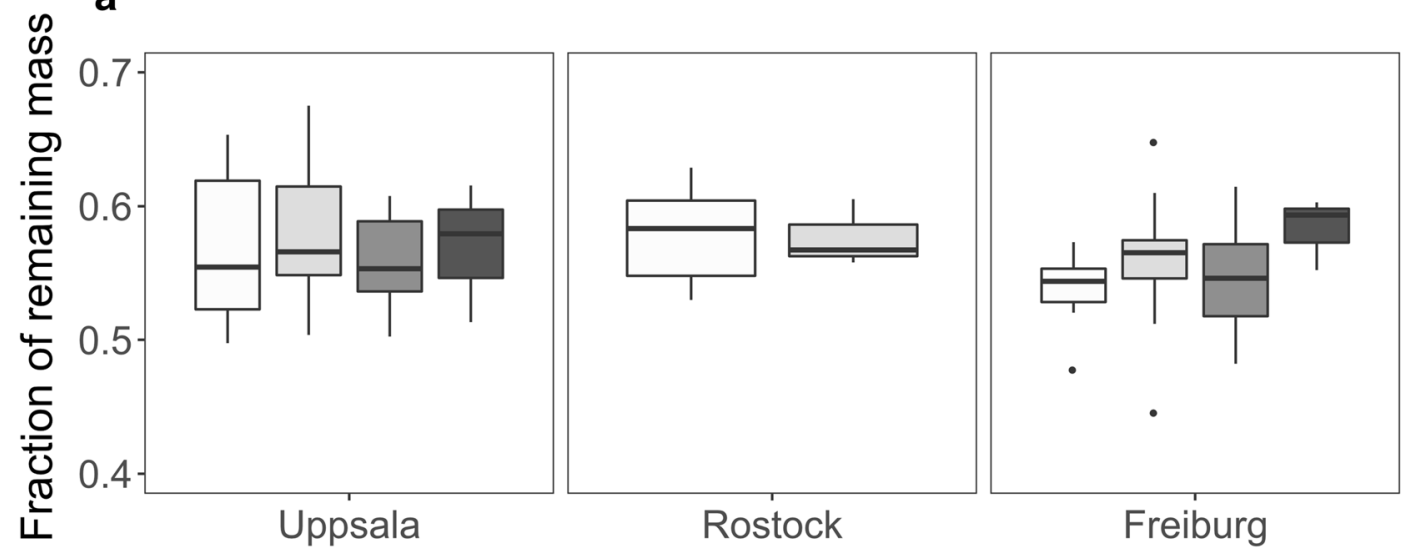

b
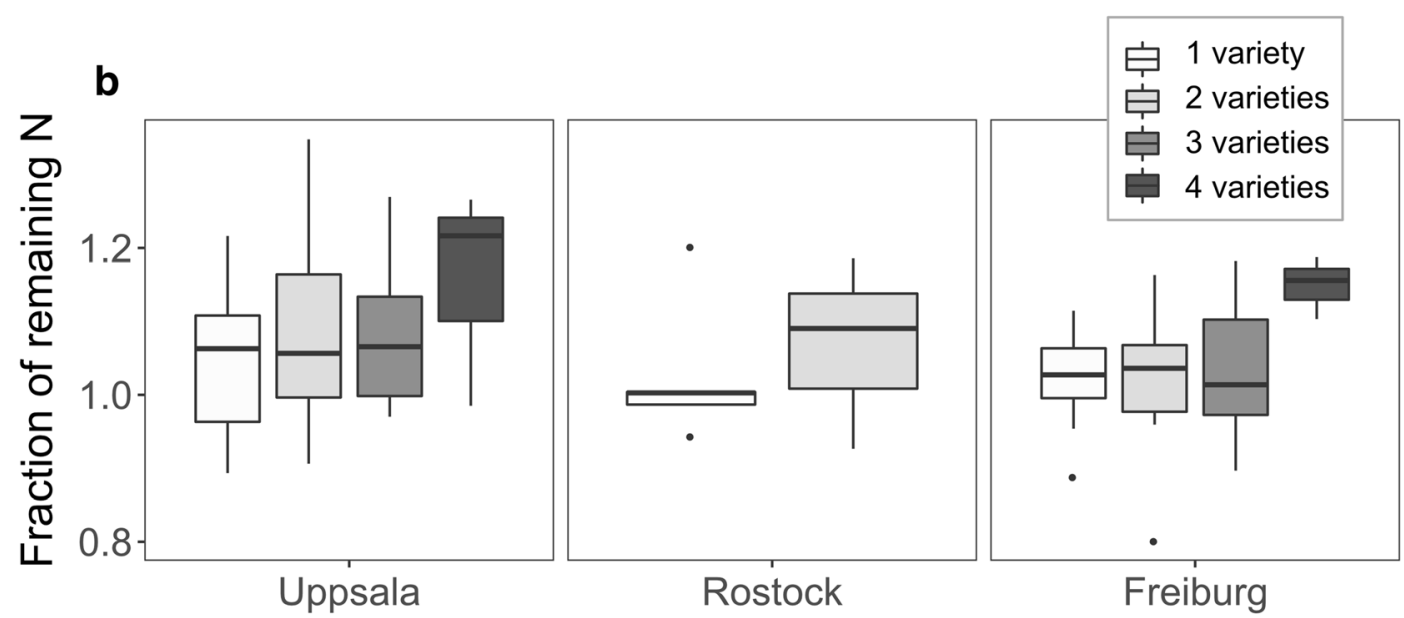

Fig. 1 Fraction of remaining mass (a) and fraction of remaining nitrogen $(\mathrm{N})(\mathbf{b})$ across the three field trials and four diversity levels (in terms of number of Salix varieties regardless of variety

identity). Differences between sites and diversity levels were tested using two-way ANOVA, and no significant differences emerged $(p>0.05)$

plots (i.e., 2 to 4 genotypes) tended to support higher fractions of remaining $\mathrm{N}$ at all sites and especially in Uppsala (Figs. $1 \mathrm{~b}$ and $3 \mathrm{e}, \mathrm{f}$ ), and higher remaining mass (i.e., lower decomposition) in Freiburg (Fig. 1), although we only found weak $(p<0.1)$ statistical support for these trends. We also found evidence for the mixture effects being additive. For example, 'Tora' exhibited slower decomposition than 'Loden' and the decomposition rate of their mixture was intermediate between the two pure cultures (Fig. 3b). This pattern was most pronounced in Uppsala followed by Rostock, resulting in significant interactions between site and variety (Fig. 3c, Table S3). The same result was obtained when using the approach presented in Section Additive vs. interactive effects of mixed litters on decomposition. The decomposition of litter mixtures was similar to the decomposition that would be expected by decomposing the constituent litter types independently (additive effects).

Specifically, the ratio of measured remaining mass and the remaining mass estimated for purely additive decomposition was significantly, but negligibly lower than one (on average $=0.99$ ). In addition, the slope of the relation between measured remaining mass and the remaining mass estimated for additive decomposition was significantly larger than one (RMA slope $=1.22$ ). A slope higher than one indicates that litter mixtures where all the constituent litter types decomposed rapidly lost mass faster than expected with only additive effects. In contrast, mixtures with constituent litters that decomposed slowly lost mass even slower than expected with only additive effects. Thus, mixtures of recalcitrant litters exhibited negative interactions. Similar results are obtained when comparing the first order decay constants of additive litter mixtures to the decay constants estimated from the observed mass loss (Supplementary Information). 

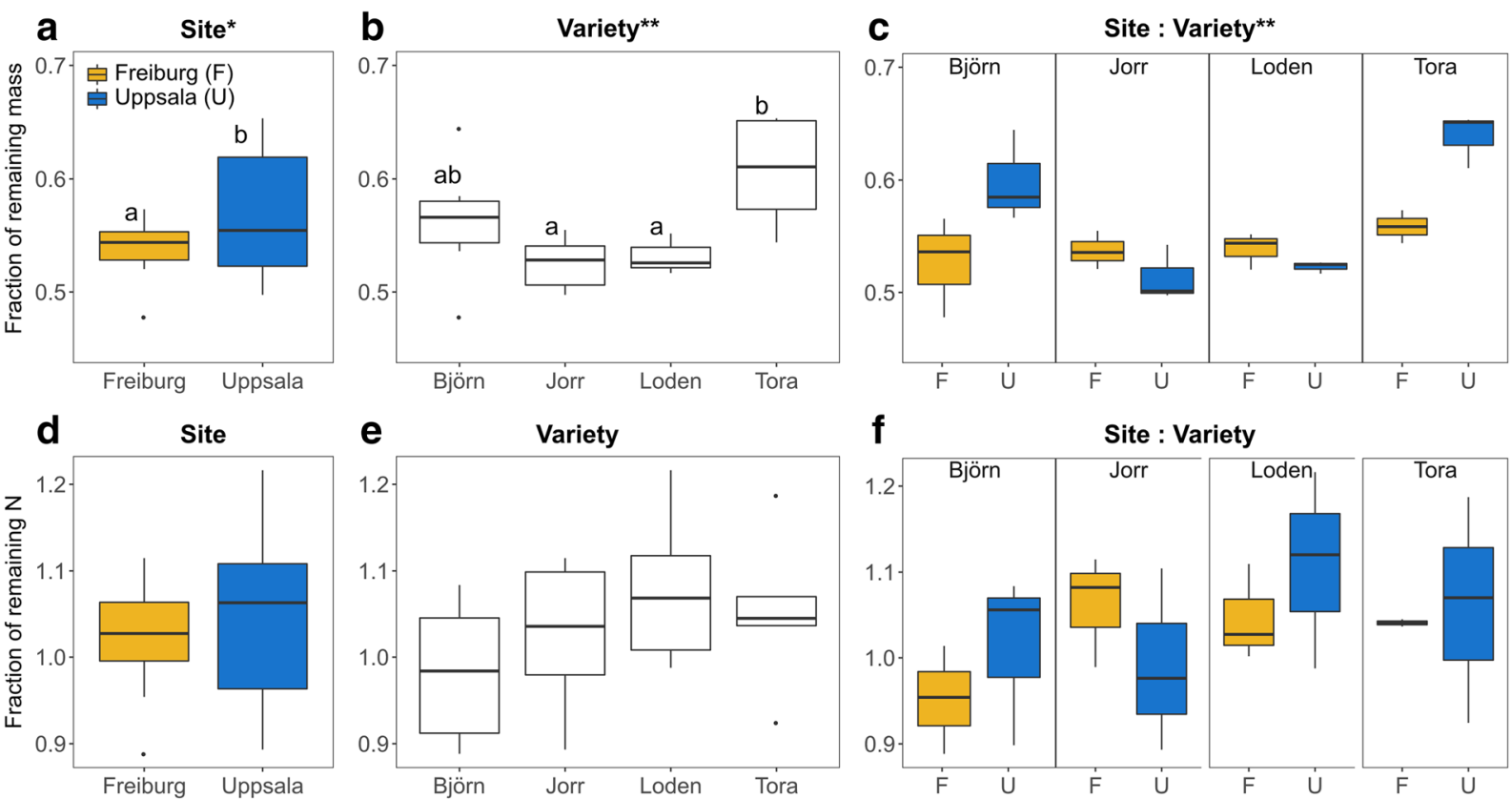

Fig. 2 Fraction of remaining mass $(\mathbf{a}-\mathbf{c})$ and nitrogen $(\mathrm{N})(\mathbf{d}-\mathbf{f})$ across the two sites Uppsala and Freiburg (a and d), the four Salix varieties 'Björn', 'Jorr', 'Loden' and 'Tora' (b and $\mathbf{e}$ ), and across the two sites in combination with the four varieties (c and f). Note that only data from monoculture plots are presented here. Asterisks

indicate the level of statistical significance by two-way ANOVA $(* p<0.05, * * p<0.01)$. Different letters indicate significant difference between sites or varieties; no letter indicate no differences (Tukey HSD, $p<0.05$ ). Detailed statistical results are reported in Table S3
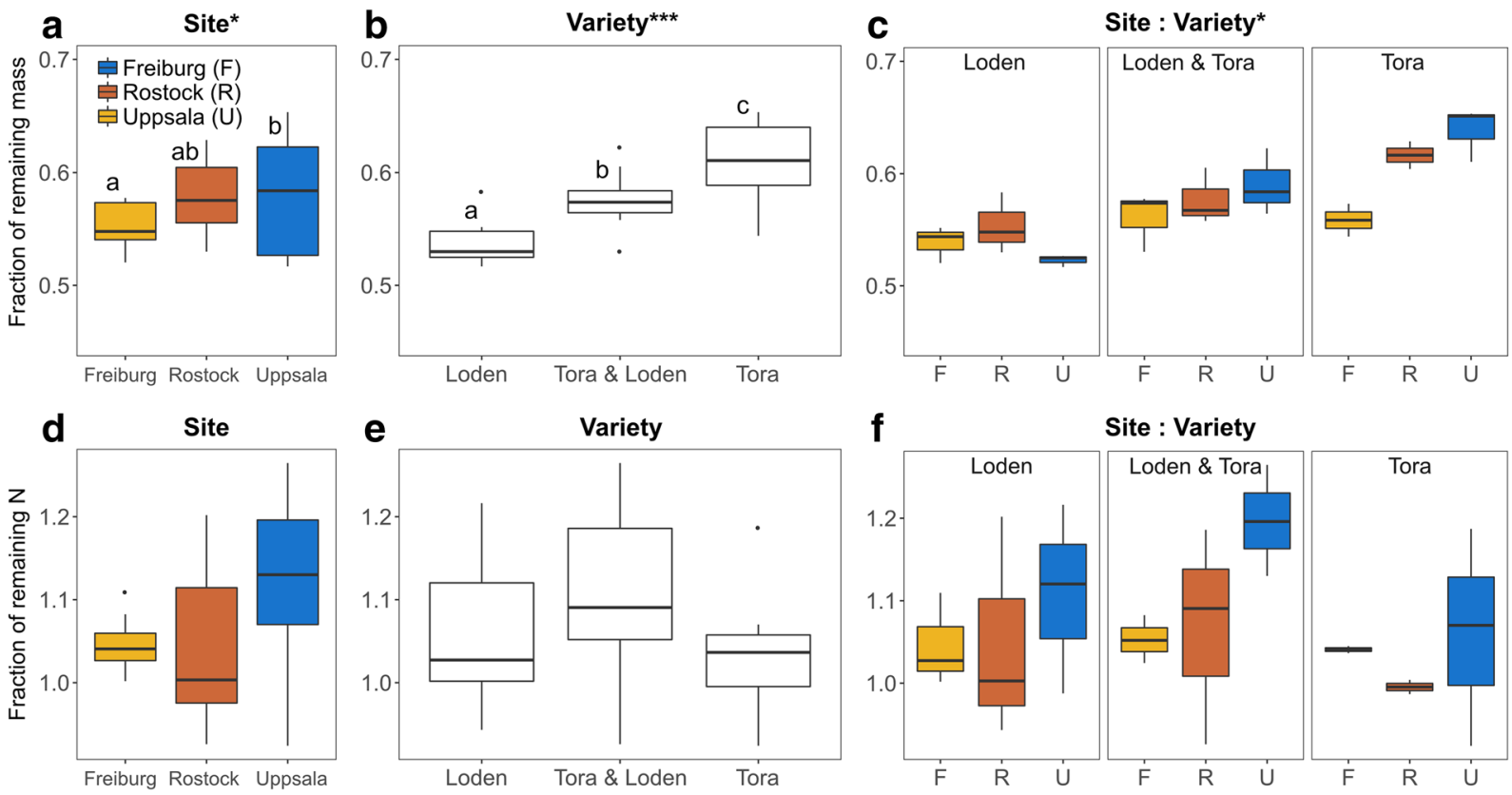

Fig. 3 Fraction of remaining mass $(\mathbf{a}-\mathbf{c})$ and nitrogen $(\mathrm{N})(\mathbf{d}-\mathbf{f})$ across the three sites Freiburg, Rostock and Uppsala (a and d), the two common Salix varieties 'Loden' and 'Tora' and their mixture (b and e), and across the three sites and the three variety treatments together (c and $\mathbf{f}$ ). Asterisks indicate the level of statistical

significance by two-way ANOVA $(* p<0.05, * * p<0.01$, $* * * p<0.001)$. Different letters indicate significant difference between sites or varieties; no letters indicate no differences (Tukey HSD, $p<0.05$ ). Detailed statistical results are reported in Table S3 
Effects of adding individual varieties to a mixture on litter decomposition (H4)

To test the effect of adding individual varieties to mixtures of other varieties, Bayesian modelling was used to evaluate the probability of an individual variety to increase or decrease decomposition when present (probability of 0.5 indicates no effect, Fig. 4). The analysis indicated consistently positive effects of 'Tora' on both remaining biomass and $\mathrm{N}$, while the taxonomically closely related genotype 'Björn' was predicted to negatively affect remaining $\mathrm{N}$ in the litter of both sites (Uppsala and Freiburg). For the varieties 'Jorr' and 'Loden', the predicted effects varied between the two sites, for instance with negative effects on the remaining biomass in Uppsala and positive effects on the remaining $\mathrm{N}$ in Freiburg (Fig. 4). In addition to that, standard linear regression models mostly confirmed the results from the Bayesian models, as shown in the Supplementary Table S4.

\section{Leaf-level predictors for litter decomposition}

Across sites and varieties, we found positive correlations between initial $\mathrm{N}$ and $\mathrm{P}$ concentrations, and negative correlations between initial $\mathrm{N}$ or $\mathrm{P}$ concentration and lignin concentration (Fig. 5, Table 1, Table S5). Some traits were good predictors of decomposition patterns. For example, higher initial $\mathrm{N}$ concentration promoted $\mathrm{N}$ loss (lower $\mathrm{N} / \mathrm{N}(0)$ ) and $\mathrm{C}$ retention (higher $\mathrm{C} / \mathrm{C}(0)$ ), whereas initial lignin concentration inhibited decomposition (positive relationship to $\mathrm{M} / \mathrm{M}(0)$ and $\mathrm{C} / \mathrm{C}(0)$ ). Litter traits varied more across sites than decomposition patterns. Initial $\mathrm{N}$ and $\mathrm{P}$ concentrations were higher, and initial lignin concentrations were lower in Uppsala compared to Rostock and especially compared to Freiburg (Figs. S4-S6), despite little site effect on remaining mass, $\mathrm{C}$, and $\mathrm{N}$ (Fig. 1).

Within sites and across varieties, additional patterns emerged (Figs. S4-S6). Initial P concentration was negatively correlated with the fraction of remaining $\mathrm{N}$ within all sites, and with the fractions of remaining mass and $\mathrm{C}$ in Uppsala. Initial lignin concentration inhibited decomposition only in Uppsala, while it had no statistically significant effect at the other two sites (despite retaining the same trend). Specific leaf area was positively correlated with initial litter $\mathrm{N}$ concentration only in Uppsala, where it also reduced decomposition, possibly due to its positive correlation with initial lignin concentration.

We also assessed whether the initial chemical properties of specific varieties explain the probabilities that adding those varieties affected decomposition and $\mathrm{N}$ mineralization (Fig. 4). Linear regressions between initial $\mathrm{N}$ and $\mathrm{P}$ concentrations and probabilities of increased mass or $\mathrm{N}$ remaining had low predictive power (coefficient of determination $\mathrm{R}^{2}$ lower than 0.4 ), except for the relation between initial $\mathrm{P}$ concentration and the probability of increasing mass remaining $\left(R^{2}=0.43\right)$. The slope of this regression was negative (though not significantly different from zero), suggesting that higher initial $\mathrm{P}$ concentration tends to promote decomposition.

\section{Discussion}

In this study, litter decomposition rates were compared across a wide geographical range but relatively narrow taxonomic range. Different from most other studies on litter decomposition that compared litter of different species or genera (Aerts 1997; Cornwell et al. 2008; Parton et al. 2007; Zhang et al. 2008), here we compared litter from four Salix varieties (hybrid willows of close taxonomic relationship). The latitudinal gradient affected litter decomposition to a lesser extent than did variety specific litter $(H 1, H 2)$. In contrast to our expectations (H3), litter decomposition did not increase with higher stand diversity; instead, certain individual varieties increased litter decomposition while others decreased it (H4).

While the range in chemical characteristics of our stand components (i.e., varieties) was smaller than the range considered in the taxonomically more diverse materials of other studies, it still spanned a relatively wide range of values - e.g. initial N, P, and lignin concentrations varied by a factor of approximately $1.5,3$, and 1.7, respectively. This variability in nutrient concentrations (especially P) was sufficient to cause significant differences between varieties and sites, causing the genotype by environment interactions in the observed decomposition patterns. These ranges in chemical composition are comparable to those found in previous studies involving genotype mixtures of angiosperm tree species, in which initial N, P and lignin concentrations varied at most by a factor of 1.7, 3.6, and 1.8, respectively, though in most mixtures, differences were smaller (LeRoy and Fischer 
Fig. 4 The posterior probability distribution shows the change in mean fraction of remaining mass $(\mathrm{M} / \mathrm{M}(0)$, black lines) and remaining nitrogen $(\mathrm{N} / \mathrm{N}(0)$, red lines) when a specific Salix variety is added to the mixture. Positive values indicate an increase in remaining mass or $\mathrm{N}$ (slower decomposition or higher $\mathrm{N}$ immobilization, respectively), and the vertical line indicates no average effect when a specific variety is added to the community. Dotted lines are from the experimental setup in Freiburg, solid lines are from Uppsala. Detailed statistical results are reported in Table S4
'Björn'

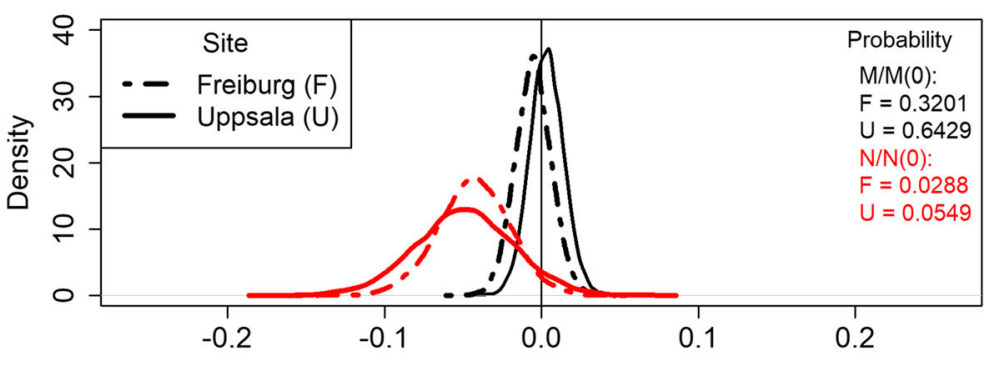

'Jorr'

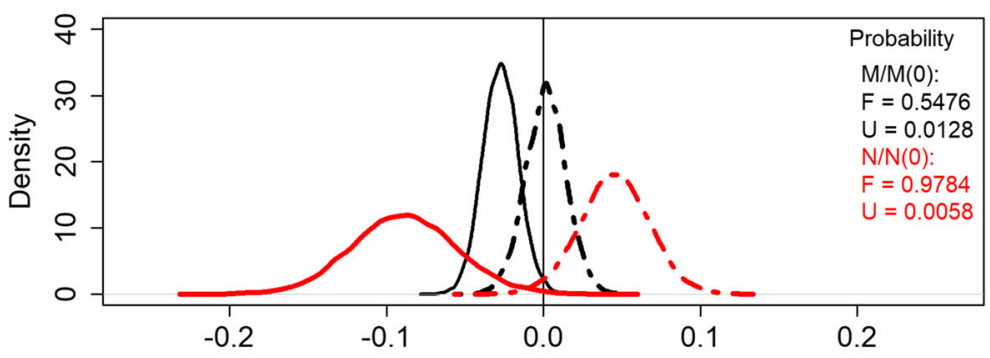

'Loden'

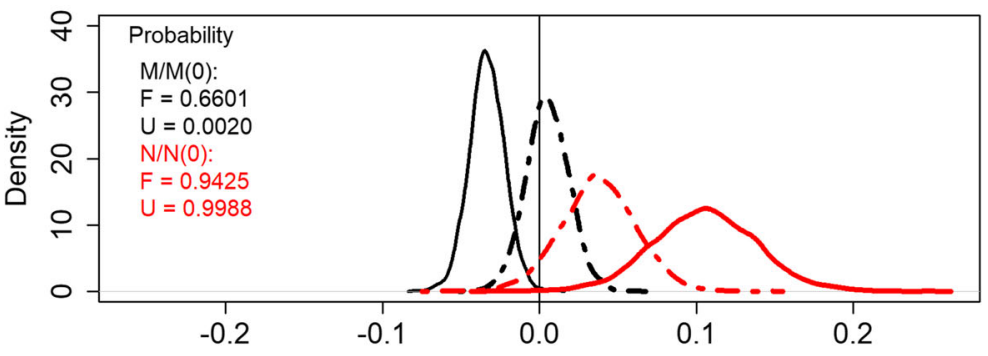

'Tora'

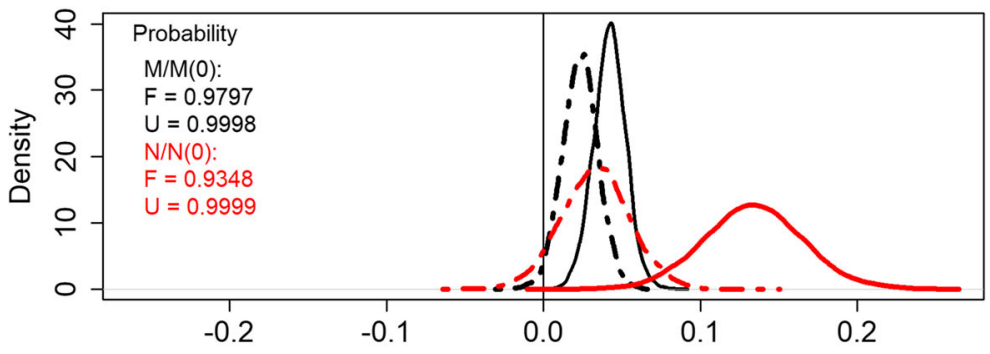

Fraction of remaining mass and nitrogen
2019; LeRoy et al. 2012; Li et al. 2017; Madritch and Hunter 2005; Schweitzer et al. 2005). In comparison, inter-specific $\mathrm{N}$ and $\mathrm{P}$ concentrations of angiosperm trees vary by factors $4-40$ and 6-100, respectively, depending on the climatic zone (data elaborated from Vergutz et al. 2012). In contrast to the large variability in nutrient concentrations, lignin concentrations vary only by a factor of five across species (Zhang et al. 2008). 


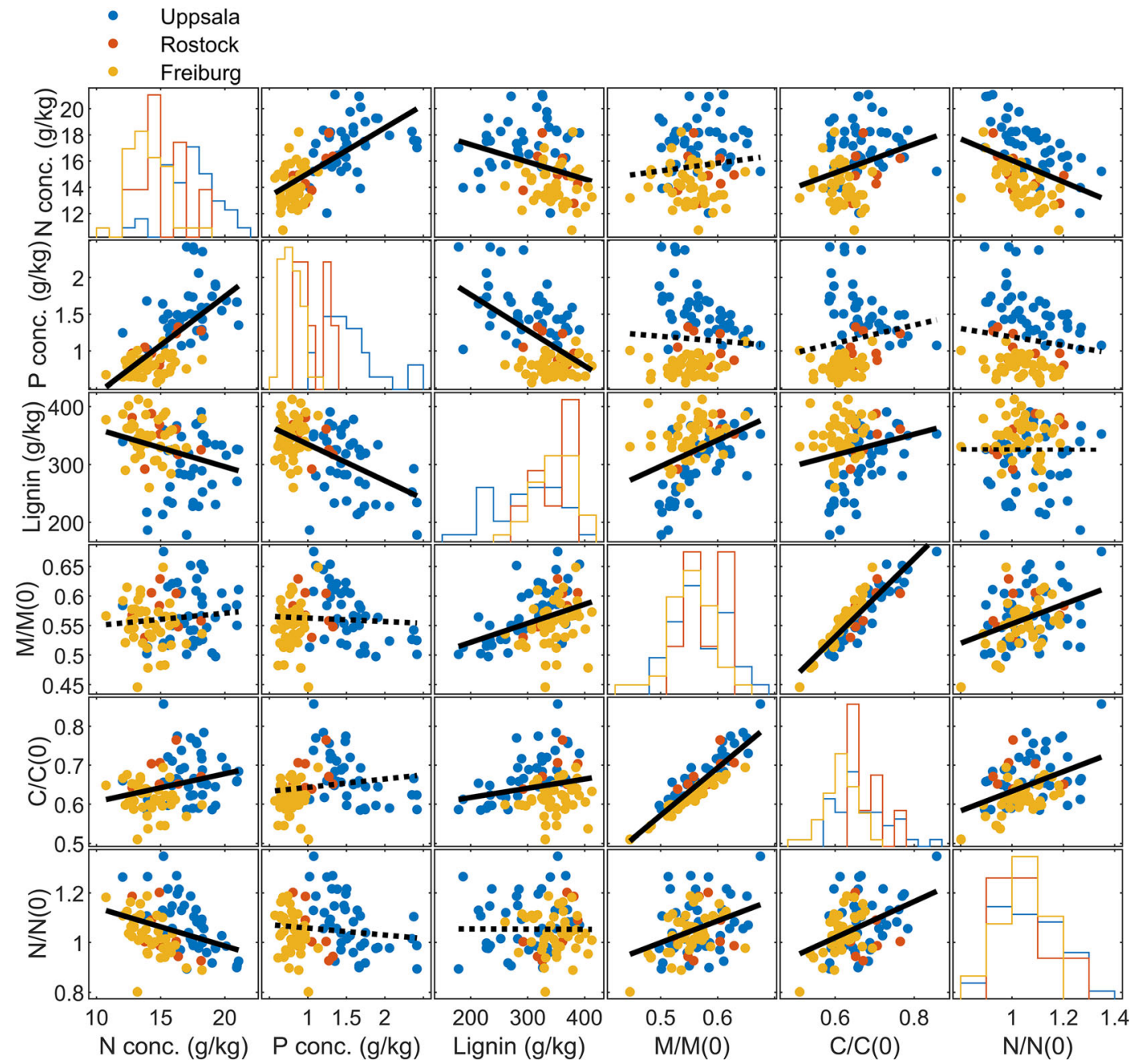

Fig. 5 Litter characteristics and decomposition patterns. Panels show histograms of (on the diagonal) or correlations among initial nitrogen, phosphorus, and lignin concentrations; fractions of remaining mass, carbon, and nitrogen (respectively $\mathrm{M} / \mathrm{M}(0), \mathrm{C} / \mathrm{C}(0)$, and $\mathrm{N} / \mathrm{N}(0)$ ). Colours indicate the field trial where litter bags were incubated. Solid black lines are ordinary least square regressions of all data with slopes significantly different from zero (dotted lines indicate non-significant slopes). Similar correlations are shown for each site separately in Figs. S4-S6

(more $\mathrm{N}$ and $\mathrm{P}$, less lignin) compared to Rostock and Freiburg. The pattern for litter quality most likely resulted from different acclimation of the plants to the local site conditions, as there is evidence for higher leaf- $\mathrm{N}$ concentrations to be an acclimation to lower air temperature (Weih and Karlsson 2001). Moreover, the original plant material had its origin from the cooler climate in Sweden.

In contrast to this rationale, macroclimatic conditions are more favourable in the Southern locations, suggesting slower decomposition when moving from Freiburg to Uppsala (Table S1). The net result of these contrasting trends was a weak site effect on the mean fraction of fraction of mass remaining) when moving from Freiburg 


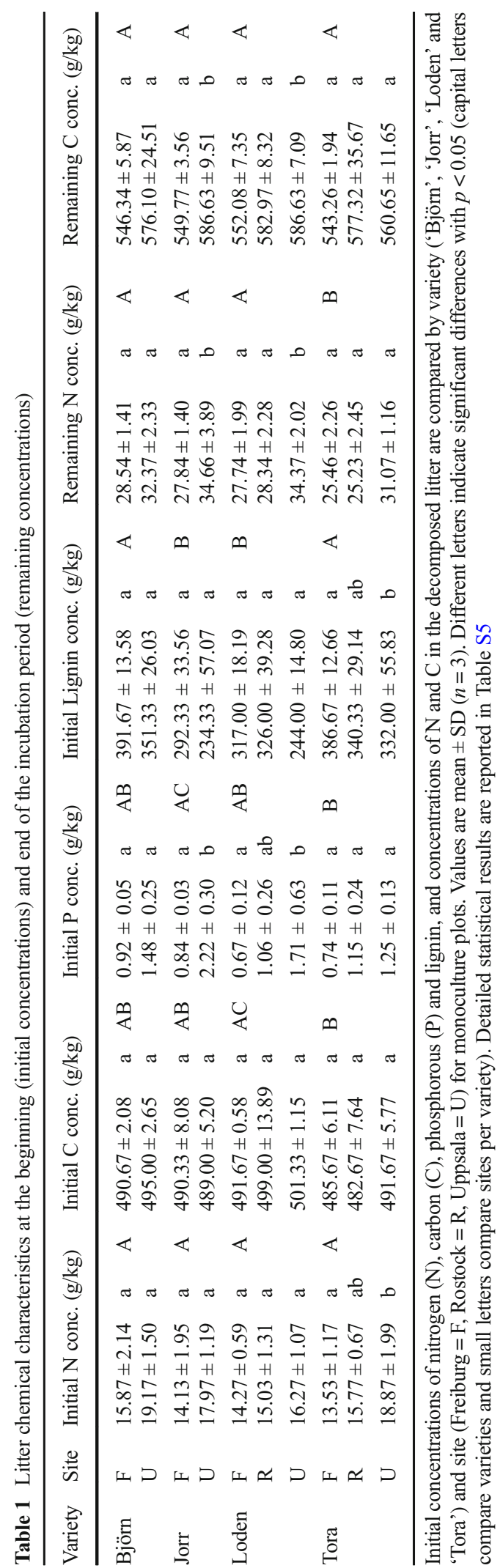

remaining mass. This finding, together with the observed small climate effect on decomposition as indicated by a standard litter type incubated at all sites (Fig. $\mathrm{S} 3$ ), suggests that climate-driven variation in decomposition was minor compared to the overall variation observed across our four varieties at any given site.

Therefore, there is little support for our H1. Earlier studies of decomposition across species and sites have also shown that within a climate region, in our case the temperate and cool-temperate zones, chemical properties are important drivers of decomposition - a role that is retained even over broader geographical areas, where climate provides an overarching control (Aerts 1997; Makkonen et al. 2012). Climate also indirectly controls decomposition by altering species composition and nutrient cycling, which determine litter chemical properties (Makkonen et al. 2012; Zhang et al. 2008). In addition to litter chemistry per se, plant traits determining litter properties (Cornwell et al. 2008) or local environmental conditions (Joly et al. 2017) can cause more variation in decomposition rates than climate even at the continental scale - a result at odds with the assumption of strong climatic control in biogeochemical models. Our findings thus confirm these results, deemphasizing climatic controls on decomposition at regional scale.

We observed $\mathrm{N}$ immobilization patterns that are in line with previous observations. Except in Rostock, where only two varieties were grown and fewer data points were available, the fraction of remaining $\mathrm{N}$ was positively (and generally strongly) correlated with the fraction of remaining mass or remaining $\mathrm{C}$ (Figs. S4 and S6). This pattern is consistent with the typical trajectory of $\mathrm{N}$ accumulation and release during decomposition - $\mathrm{N}$ continues to accumulate as mass (and C) is lost until a 'critical' $\mathrm{C}: \mathrm{N}$ ratio is attained, at which point $\mathrm{N}$ is mineralized (Berglund et al. 2013; Manzoni et al. 2010; Parton et al. 2007). Moreover, the fractions of remaining $\mathrm{N}$ typically exceeded one when the fractions of remaining mass were higher, indicating that $\mathrm{N}$ was immobilized in litter types that were decomposing slowly due to $\mathrm{N}$ limitation of the microbial community. In fact, the amount of immobilized $\mathrm{N}$ was higher when the initial $\mathrm{N}$ concentration was lower (negative correlation between $\mathrm{N} / \mathrm{N}(0)$ and initial $\mathrm{N}$ concentration). Thus, $\mathrm{N}$ immobilization appears to be driven by initial litter $\mathrm{N}$ concentration. 
Site-specific decomposition of monospecific litter of the four varieties

Examining the decomposition of monotypic litter across sites and varieties, we found that climatic conditions had minor effects compared to the chemical properties and identity of the litter, supporting the first part of our $\mathrm{H} 2$ (litter variety identity is a strong driver for its decomposition). However, when we tested whether litter decomposition behaves similarly among sites, we had to reject the second part of $H 2$ (differences in decomposition among litters are conserved across the latitudinal gradient) as we could observe significant differences in decomposition between sites and varieties grown in monoculture (Figs. 2 and 3).

The comparison between the two taxonomically most distant varieties 'Loden' and 'Tora' showed sitespecific patterns in decomposition and remaining $\mathrm{N}$ (Fig. 3, interaction between site and genotype), where the similar decomposition of 'Loden' among sites seemed to be caused by differences in chemical composition and the different decomposition of 'Tora' among sites by variations in climate. Specifically, the decomposition of the relatively high-quality 'Loden' litter was faster in the Northern site (Uppsala) (Fig. 3), where initial lignin concentration was lower and $\mathrm{P}$ concentration was higher (Table 1). Both $\mathrm{P}$ and $\mathrm{N}$ can be limiting for litter decomposers because litter $\mathrm{P}$ and $\mathrm{N}$ concentrations are much lower than those required by microorganisms to grow (Enriquez et al. 1993; Manzoni et al. 2010). However, in this case the almost three-fold higher $\mathrm{P}$ concentration in the North (Uppsala) compared to the South (Freiburg) suggests that P rather than N could be driving a South-North increasing decomposition trend that more than compensates for the less favourable climatic conditions in the South (Uppsala) (Table S1). In contrast, 'Tora' litter decomposed faster in most Southern site (Freiburg) compared to the both Northern sites (Rostock and Uppsala), despite decreasing initial lignin and increasing initial $\mathrm{P}$ concentrations in 'Tora' litter from South to North. Therefore, the decomposition of 'Tora' seems to be consistent with $H 1$, decreasing from Central to Northern Europe, whereas decomposition of 'Loden' is driven by litter quality. Despite the faster mass loss, remaining $\mathrm{N}$ of 'Loden' was higher in the most Northern Site (Uppsala), indicating that more $\mathrm{N}$ was immobilized in the North (Uppsala) than in the South (Freiburg and Rostock). We propose that 'Loden' litter in the North (Uppsala) has accumulated more $\mathrm{N}$ than in the South (Freiburg) because it has reached a later stage in decomposition, and is thus about to start releasing $\mathrm{N}$.

On the one hand, the specific climatic or edaphic conditions in Freiburg reduced the effects of differences in litter chemistry among varieties, resulting in similar decomposition rates among the varieties grown at that site (Fig. 2). Moreover, in Freiburg and Rostock (Fig. S5-S6), neither lignin nor $\mathrm{N}$ or $\mathrm{P}$ concentrations were consistently linked to decomposition, which is in contrast to previous studies (Melillo et al. 1982; Osono and Takeda 2005; Setiawan et al. 2016). On the other hand, in Uppsala decomposition was more dependent on $\mathrm{P}$ and lignin than $\mathrm{N}$ availability, and thus contrasts in litter chemistry appeared to be a strong driver of decomposition (Fig. S4). Osono and Takeda (2005) studied 14 litter types in the cool temperate zone and found no relationship between $\mathrm{N}$ and mass loss, whereas lignin was negatively related to decomposition rate. It seems that in some cool temperate zones, like Uppsala, decomposition might be less affected by $\mathrm{N}$ availability and more by lignin and potentially $\mathrm{P}$ as in our case. In addition, the overall relationship between $\mathrm{N}: \mathrm{P}$ and decomposition of all pure cultures in Uppsala was significantly negative, but this negative relationship seemed to be variety dependent (effect not significant due to the lack of replicates). Taken together, variety-specific chemical properties seemed to be a strong driver of decomposition in Uppsala whereas decomposition seemed to be mostly driven by the specific climatic or edaphic conditions in Freiburg.

Mixing litter of the four varieties did not affect decomposition

We hypothesised that mixing litter of different varieties with contrasting nutrient and lignin concentrations, should decompose faster than the average of the litter from the monocultures (H3). This expectation is motivated by nutrient transfer among leaves of different chemical composition that improves the nutrient status of the decomposers (Berglund and Ågren 2012; Handa et al. 2014; Manzoni et al. 2008; Schimel and Hättenschwiler 2007). However, synergistic effects may also occur, as suggested by the faster rates of release (or slower immobilization) of $\mathrm{N}$ and $\mathrm{P}$ observed in intra-specific litter mixtures (Schweitzer et al. 2005; Wang et al. 2014). Hypothesis $H 3$ was rejected since decomposition neither increased nor decreased with 
increasing genetic richness (Fig. 1), which is consistent with other studies of decomposition of intra-specific litter mixtures (Crutsinger et al. 2009; Madritch et al. 2006), and more in general with the lack of predictable interactive effects on decomposition in inter-specific mixtures (Porre et al. 2020).

\section{Additive decomposition responses and increased $\mathrm{N}$} immobilization in mixed litter

In this study, we could address the mechanisms of mixing litter by comparing monospecific and mixed litter decomposition of the varieties 'Loden' and 'Tora', which have contrasting characteristics and were grown at all field sites. We observed an additive effect where decomposition of mixed litter of 'Loden' and 'Tora' was generally faster than single litter of 'Loden', but slower than for 'Tora' litter alone (Fig. 3b). This additive effect was very pronounced in Uppsala followed by Rostock. In Freiburg we observed an antagonistic, non-additive effect, where the mixture of 'Loden' and 'Tora' had a slightly lower decomposition rate than both monocultures. This antagonistic effect is not uncommon, as previous studies with mixed litter have shown that decomposition rates can be higher or lower than in monocultures (reviewed by Gartner and Cardon 2004; Porre et al. 2020). The intermediate decomposition of the 'Loden'- 'Tora' mixture in Uppsala might have been driven by leaf chemical properties, because 'Loden' has lower initial lignin and higher initial $\mathrm{P}$ concentration than 'Tora' (this was not the case in Freiburg, where these two litter types were more similar; Table 1).

Furthermore, $\mathrm{N}$ accumulated more in decomposing litter mixtures than in monotypic litters (Fig. 3). This pattern could be explained by high transfer of $\mathrm{N}$ from relatively $\mathrm{N}$-rich leaves to relatively $\mathrm{N}$-poor leaves (Berglund et al. 2013; Schimel and Hättenschwiler 2007). Thanks to the tight contact between litter types with contrasting properties, $\mathrm{N}$ released by $\mathrm{N}$-rich leaves could be easily immobilized by microorganisms feeding on the N-poor leaves, reducing $\mathrm{N}$ losses via leaching and promoting $\mathrm{N}$ retention. Taken together, the combination of different lignin and $\mathrm{P}$ concentrations as well as leaf area ratio (i.e., total leaf area per total plant biomass; e.g., Hoeber et al. (2018)) between the two contrasting varieties 'Loden' and 'Tora' could explain the intermediate decomposition of the two-variety mixture, whereas $\mathrm{N}$ transfer might explain the higher $\mathrm{N}$ accumulation in the two-variety mixture.
Site-specific effects of variety presence on decomposition

The presence of a specific Salix variety affected decomposition differently between Freiburg and Uppsala (Fig. 4). On the one hand and in line with our fourth hypothesis (H4), the fast-decomposing varieties 'Jorr' and 'Loden' were likely to increase decomposition. On the other hand, the presence of the slower-decomposing variety 'Tora' was very likely to decrease decomposition. These results are expected since litter from a fastdecomposing variety might speed up decomposition of more recalcitrant or nutrient-poor litter by releasing $\mathrm{N}$ or P (Hättenschwiler et al. 2005). In this case, 'Loden' litter - despite having a slightly lower initial N concentration than the other varieties in some sites - probably reached faster the 'critical' point at which $\mathrm{N}$ is released and can be immobilized by other litter types. Furthermore, the presence of 'Tora' was likely to increase remaining N, confirming the above-mentioned findings of a higher remaining $\mathrm{N}$ when 'Loden' and 'Tora' were incubated together (Fig. 3). Interestingly, the two siblings 'Björn' and 'Tora', despite their taxonomical similarity, showed comparable effects on both mass and $\mathrm{N}$ remaining that were consistent between sites, but not between each other (Fig. 4). Therefore, the presence of specific varieties can either promote or decrease decomposition and nutrient mineralization depending on the site and variety identity, as hypothesized in $H 4$.

\section{Conclusions}

Overall, this study demonstrates that different stand components, here Salix varieties, produce litter of contrasting quality when grown under different site conditions (here latitudinal and edaphic gradients), leading to differences in decomposition due to either litter quality and/or climatic or edaphic conditions. Macroclimatic conditions did affect litter decomposition of specific varieties, but did not affect overall litter decomposition and $\mathrm{N}$ release. The local soil conditions appeared to be a strong driver of decomposition only at one (i.e., the southern) site, whereas at another (i.e., the northern) site, litter quality ( $\mathrm{P}$ and lignin concentration, but not $\mathrm{N})$ played a more important role already at this early stage of the decomposition process. In addition to the above findings, litter diversity per se did not affect litter decomposition. Our findings show that decomposition 
dynamics were enhanced with the presence of fastdecomposing stand components (here varieties), suggesting that plants with favorable litter quality for decomposition (i.e., high $\mathrm{P}$ and low lignin content) can speed up decomposition of the litter of the whole plant community.

Acknowledgments We thank Inés Prieto-Ruiz for helping to prepare litter bags; Nils-Erik Nordh, Maria Kedmark, Ewa Magnuski and Maria Jonsson for technical assistance; Elan Swartz, Robin Hagblom, Yvonne Smith, Lucia Rivero and Marielle for placing litter bags; Gabriele Toma and Clara Arranz from Freiburg as well as Christel Baum from Rostock for collecting and sending litter material and litter bags to Sweden, and Matt Low for the inspiring support on Bayesian models. Two reviewers are also acknowledged for their constructive criticism. SM and MW were supported by the Swedish Research Council Formas (2016-00998); the project at the Uppsala ECOLINK-Salix site was partly funded by the Swedish Energy Agency (36654-1, 36654-2, 36654-3).

Funding Information Open access funding provided by Swedish University of Agricultural Sciences.

Open Access This article is licensed under a Creative Commons Attribution 4.0 International License, which permits use, sharing, adaptation, distribution and reproduction in any medium or format, as long as you give appropriate credit to the original author(s) and the source, provide a link to the Creative Commons licence, and indicate if changes were made. The images or other third party material in this article are included in the article's Creative Commons licence, unless indicated otherwise in a credit line to the material. If material is not included in the article's Creative Commons licence and your intended use is not permitted by statutory regulation or exceeds the permitted use, you will need to obtain permission directly from the copyright holder. To view a copy of this licence, visit http://creativecommons.org/licenses/by/4.0/.

\section{References}

Aerts R (1997) Climate, leaf litter chemistry and leaf litter decomposition in terrestrial ecosystems: a triangular relationship. Oikos 79:439-449

Ågren GI, Weih M (2012) Plant stoichiometry at different scales: element concentration patterns reflect environment more than genotype. New Phytol 194:944-952

Austin AT, Vivanco L, Gonzalez-Arzac A, Perez LI (2014) There's no place like home? An exploration of the mechanisms behind plant litter- decomposer affinity in terrestrial ecosystems. New Phytol 204:307-314. https://doi.org/10.1111 /nph.12959

Ball BA, Bradford MA, Hunter MD (2009) Nitrogen and phosphorus release from mixed litter layers is lower than predicted from single species decay. Ecosystems 12:87-100
Barantal S, Roy J, Fromin N, Schimann H, Hättenschwiler S (2011) Long-term presence of tree species but not chemical diversity affect litter mixture effects on decomposition in a neotropical rainforest. Oecologia 167:241-252. https://doi. org/10.1007/s00442-011-1966-4

Berg B, McClaugherty CA (2003) Plant litter. Decomposition, humus formation, carbon sequestration. Springer, Berlin

Berglund SL, Ågren GI (2012) When will litter mixtures decompose faster or slower than individual litters? A model for two litters. Oikos 121:1112-1120. https://doi.org/10.1111/j.16000706.2011.19787.x

Berglund SL, Ågren GI, Ekblad A (2013) Carbon and nitrogen transfer in leaf litter mixtures. Soil Biol Biochem 57:341348. https://doi.org/10.1016/j.soilbio.2012.09.015

Cornwell WK, Cornelissen JHC, Amatangelo K, Dorrepaal E, Eviner VT, Godoy O, Hobbie SE, Hoorens B, Kurokawa H, PérezHarguindeguy N, Quested HM, Santiago LS, Wardle DA, Wright IJ, Aerts R, Allison SD, van Bodegom P, Brovkin V, Chatain A, Callaghan TV, Díaz S, Garnier E, Gurvich DE, Kazakou E, Klein JA, Read J, Reich PB, Soudzilovskaia NA, Vaieretti MV, Westoby M (2008) Plant species traits are the predominant control on litter decomposition rates within biomes worldwide. Ecol Lett 11:1065-1071

Cotrufo MF, Wallenstein MD, Boot CM, Denef K, Paul E (2013) The microbial efficiency-matrix stabilization (MEMS) framework integrates plant litter decomposition with soil organic matter stabilization: do labile plant inputs form stable soil organic matter? Glob Chang Biol 19:988-995. https://doi.org/10.1111/gcb.12113

Crutsinger GM, Sanders NJ, Classen AT (2009) Comparing intraand inter-specific effects on litter decomposition in an oldfield ecosystem. Basic Appl Ecol 10:535-543

Djukic I et al (2018) Early stage litter decomposition across biomes. Sci Total Environ 628-629:1369-1394. https://doi. org/10.1016/j.scitotenv.2018.01.012

Enriquez S, Duarte CM, Sandjensen K (1993) Patterns in decomposition rates among photosynthetic organisms - the importance of detritus C-N-P content. Oecologia 94:457-471. https://doi.org/10.1007/Bf00566960

Gartner TB, Cardon ZG (2004) Decomposition dynamics in mixed-species leaf litter. Oikos 104:230-246. https://doi. org/10.1111/j.0030-1299.2004.12738.x

Gelman A, Rubin DB (1992) Inference from iterative simulation using multiple sequences. Stat Sci 7:457-472

Handa IT et al (2014) Consequences of biodiversity loss for litter decomposition across biomes. Nature 509:218-221. https://doi.org/10.1038/nature13247

Hättenschwiler S, Tiunov AV, Scheu S (2005) Biodiversity and litter decomposition in terrestrial ecosystems. Ann Rev Ecol Evol Syst 36:191-218. https://doi.org/10.1146/annurev. ecolsys.36.112904.151932

Hobbs NT, Hooten MB (2015) Bayesian models: a statistical primer for ecologists. Princeton University Press, Princeton

Hoeber S et al (2018) Genotype identity has a more important influence than genotype diversity on shoot biomass productivity in willow short-rotation coppices Gcb. Bioenergy 10 : 534-547. https://doi.org/10.1111/gcbb.12521

Jacob M, Weland N, Platner C, Schaefer M, Leuschner C, Thomas FM (2009) Nutrient release from decomposing leaf litter of temperate deciduous forest trees along a gradient of increasing tree species diversity. Soil Biol Biochem 41:2122-2130 
Jewell MD, Shipley B, Low-Decarie E, Tobner CM, Paquette A, Messier C, Reich PB (2017) Partitioning the effect of composition and diversity of tree communities on leaf litter decomposition and soil respiration. Oikos 126:959-971. https://doi.org/10.1111/oik.03868

Joly FX et al (2017) Tree species diversity affects decomposition through modified micro-environmental conditions across European forests. New Phytol 214:1281-1293. https://doi. org/10.1111/nph.14452

Kuzovkina YA et al (2008) Salix: botany and global horticulture. Hortic Rev 34:447-489

Larsson S (1998) Genetic improvement of willow for shortrotation coppice. Biomass Bioenergy 15:23-26

LeRoy CJ, Fischer DG (2019) Do genetically-specific tree canopy environments feed back to affect genetically specific leaf decomposition rates? Plant Soil 437:1-10. https://doi. org/10.1007/s11104-019-03952-y

LeRoy CJ, Wooley SC, Lindroth RL (2012) Genotype and soil nutrient environment influence aspen litter chemistry and instream decomposition. Freshwater Science 31:1244-1253

Li SS, Tong YW, Wang ZW (2017) Species and genetic diversity affect leaf litter decomposition in subtropical broadleaved forest in southern China. J Plant Ecol 10:232-241. https://doi.org/10.1093/jpe/rtw122

Madritch MD, Hunter MD (2005) Phenotypic variation in oak litter influences short-and long-term nutrient cycling through litter chemistry. Soil Biol Biochem 37:319-327

Madritch M, Donaldson JR, Lindroth RL (2006) Genetic identity of Populus tremuloides litter influences decomposition and nutrient release in a mixed forest stand. Ecosystems 9:528-537

Makkonen M, Berg MP, Handa IT, Hättenschwiler S, van Ruijven J, van Bodegom PM, Aerts R (2012) Highly consistent effects of plant litter identity and functional traits on decomposition across a latitudinal gradient. Ecol Lett 15:1033-1041

Manzoni S, Porporato A, Schimel JP (2008) Soil heterogeneity in lumped mineralization-immobilization models. Soil Biol Biochem 40:1137-1148

Manzoni S, Trofymow JA, Jackson RB, Porporato A (2010) Stoichiometric controls dynamics on carbon, nitrogen, and phosphorus in decomposing litter. Ecol Monogr 80:89-106

McElreath R (2015) Statistical rethinking. Texts in statistical science. CRC Press

Melillo JM, Aber JD, Muratore JF (1982) Nitrogen and lignin control of hardwood leaf litter decomposition dynamics. Ecology 63:621-626. https://doi.org/10.2307/1936780

Osono T, Takeda H (2005) Decomposition of organic chemical components in relation to nitrogen dynamics in leaf litter of 14 tree species in a cool temperate forest. Ecol Res 20:41-49. https://doi.org/10.1007/s11284-004-0002-0

Parton W et al (2007) Global-scale similarities in nitrogen release patterns during long-term decomposition. Science 315:361-364

Plummer M (2003) JAGS: a program for analysis of Bayesian graphical models using Gibbs sampling. In: Proceedings of the 3rd international workshop on distributed statistical computing. Vienna, Austria, p 125
Porre RJ, van der Werf W, De Deyn GB, Stomph TJ, Hoffland E (2020) Is litter decomposition enhanced in species mixtures? A meta-analysis. Soil Biol Biochem 145:107791

R Core Team (2019) R: a language and environment for statistical computing. R Foundation for Statistical Computing, Vienna

Scherer-Lorenzen M (2008) Functional diversity affects decomposition processes in experimental grasslands. Funct Ecol 22: 547-555. https://doi.org/10.1111/j.1365-2435.2008.01389.x

Schimel JP, Hättenschwiler S (2007) Nitrogen transfer between decomposing leaves of different N status. Soil Biol Biochem 39:1428-1436

Schweitzer JA, Bailey JK, Hart SC, Whitham TG (2005) Nonadditive effects of mixing cottonwood genotypes on litter decomposition and nutrient dynamics. Ecology 86:2834 2840. https://doi.org/10.1890/04-1955

Setiawan NN, Vanhellemont M, De Schrijver A, Schelfhout S, Baeten L, Verheyen K (2016) Mixing effects on litter decomposition rates in a young tree diversity experiment. Acta Oecologica-International Journal of Ecology 70:79-86. https://doi.org/10.1016/j.actao.2015.12.003

Silfver T, Mikola J, Rousi M, Roininen H, Oksanen E (2007) Leaf litter decomposition differs among genotypes in a local Betula pendula population. Oecologia 152:707-714. https://doi.org/10.1007/s00442-007-0695-1

Vergutz L, Manzoni S, Porporato A, Novais RF, Jackson RB (2012) Global resorption efficiencies and concentrations of carbon and nutrients in leaves of terrestrial plants. Ecol Monogr 82:205-220

Vivanco L, Austin AT (2008) Tree species identity alters forest litter decomposition through long-term plant and soil interactions in Patagonia, Argentina. J Ecol 96:727-736. https://doi.org/10.1111/j.1365-2745.2008.01393.x

Wang X-Y, Miao Y, Yu S, Chen X-Y, Schmid B (2014) Genotypic diversity of an invasive plant species promotes litter decomposition and associated processes. Oecologia 174:993-1005

Weih M, Karlsson PS (2001) Growth response of mountain birch to air and soil temperature: is increasing leaf-nitrogen content an acclimation to lower air temperature? New Phytol 150:147-155

Weih M, Nordh N-E (2002) Characterising willows for biomass and phytoremediation: growth, nitrogen and water use of 14 willow clones under different irrigation and fertilisation regimes. Biomass Bioenergy 23:397-413

Weih M, Glynn C, Baum C (2019) Willow short-rotation coppice as model system for exploring ecological theory on biodiversity-ecosystem function. Diversity-Basel 11. https://doi.org/10.3390/d11080125

Zhang D, Hui D, Luo Y, Zhou G (2008) Rates of litter decomposition in terrestrial ecosystems: global patterns and controlling factors. J Plant Ecol 1:85-93

Publisher's note Springer Nature remains neutral with regard to jurisdictional claims in published maps and institutional affiliations. 